Manuscript Number: RENE-D-16-00391

Title: Crack characterisation using invariable feature extraction in stainless steel specimen used for absorber tubes of CSP applications via EMAT

Article Type: Research Paper

Keywords: Electromagnetic acoustic transducer; stainless steel; crack; non-destructive testing and evaluation; invariable feature

Corresponding Author: Dr. Liang Cheng, PhD

Corresponding Author's Institution: Brunel University

First Author: Liang Cheng, PhD

Order of Authors: Liang Cheng, PhD; Maria Kogia; Abbas Mohimi; Vassilios Kappatos; Cem Selcuk; Tat-Hean Gan

Abstract: Absorber tubes are one of the most critical components of parabolic trough Concentrated Solar Plants. Due to the high temperatures where these tubes perform at with concentration of sunlight, it is very likely to get damaged such as crack etc and lose functionality. Therefore, the monitoring via NDT techniques is essential for preventing them from being significantly defective and reducing maintenance cost. Non-contact method is one of the best inspection candidates, which is more reliable to the tubes at high temperature through a review and the access to the absorber tubes is limited. In this paper, the crack detection and quantification for stainless steel specimen used for absorber tube using Electromagnetic Acoustic Transducers is presented. Through numerical and experimental studies, features are extracted to quantify the crack. Among these features, the ratio between the first edge echo and the second crack echo (Ac2/Ae1) is investigated as invariable feature to factors such as electromagnetic coupling, lift-off distance between EMATs and the specimen etc. In addition, the feature Ac2/Ae1 has linear relationship with the depth of the crack when the depth is more than $0.75 \mathrm{~mm}$, which proves the feature Ac2/Ae1 is invariable for crack quantification via both numerical modelling and experimental studies.

Suggested Reviewers: Yunze He PhD

Professor, Department of Instrumentation Science and Technology, National University of Defense Technology

hejicker@163.com

He worked in NDT and SHM using Electromagnetic methods for 10 years. The applications cover wind energy, solar industry.

Bin Gao PhD

Associate Professor, Automation, University of Electronic Science and Technology of China

bin_gao@uestc.edu.cn 
He has solid experience in NDT and signal processing for wind and solar industries. He is a good reviewer for my paper on the defect

characterisation

Yong Li PhD

Associate Professor, Xi'an Jiao Tong University, China

yong.li@mail.xjtu.edu.cn

He had expertise in NDT especially simulation modelling in

Electromagnetics. He is ideal reviewer for the validation of simulation and experiment studies using EMAT for my paper 
03/02/2016

Dear whom it may concerns

I would like to submit the attached manuscript, "Crack characterisation using invariable feature extraction in stainless steel specimen used for absorber tubes of CSP applications via EMAT" for consideration for possible publication in the Renewable Energy. The follows are the abstract of this manuscript. Thanks a lot.

\title{
Crack characterisation using invariable feature extraction in stainless steel specimen used for absorber tubes of CSP applications via EMAT
}

\begin{abstract}
Absorber tubes are one of the most critical components of parabolic trough Concentrated Solar Plants (CSPs). Due to the high temperatures where these tubes perform at with concentration of sunlight, it is very likely for them to get damaged such as crack and mass loss etc., and lose functionality of power generation. Therefore, the monitoring of their structural health via Non-Destructive Testing (NDT) techniques is regarded as essential for preventing them from being significantly defective and thereby reducing maintenance cost. Non-contact method is one of the best inspection candidates, which is more reliable to the tubes at high temperature through a review and the access to the absorber tubes is limited. In this paper, the crack detection and quantification for stainless steel specimen used for absorber tube using Electromagnetic Acoustic Transducers (EMATs) is presented. Through numerical and experimental studies, features are extracted to quantify the crack. Among these features, the ratio between the first edge echo and the second crack echo $\left(\mathrm{A}_{\mathrm{c} 2} / \mathrm{A}_{\mathrm{e} 1}\right)$ is investigated as invariable feature to factors such as electromagnetic coupling, lift-off distance between EMATs and the specimen etc. In addition, the feature $A_{\mathrm{c} 2} / A_{\mathrm{e} 1}$ has linear relationship with the depth of the crack when the depth is more than $0.75 \mathrm{~mm}$, which proves the feature $\mathrm{A}_{\mathrm{c} 2} / \mathrm{A}_{\mathrm{e} 1}$ is invariable for crack quantification via both numerical modelling and experimental studies.
\end{abstract}

Corresponding Author 1: Dr Liang Cheng

Brunel Innovation Centre, Brunel University, UK

Email: bic@brunel.ac.uk, liang.cheng@brunel.ac.uk

Corresponding Author 2: Prof. Tat-Hean Gan

Brunel Innovation Centre, Brunel University, UK; TWI Ltd, UK

Email: tat-hean.gan@brunel.ac.uk

\section{Best Regards}

\section{Liang Cheng}


Highlights:

- Crack detection and quantification for stainless steel specimen used for absorber tubes of CSP plants using Electromagnetic Acoustic Transducers (EMATs) is developed

- An feature invariable to factors such as electromagnetic coupling, lift-off distance between EMATs and the specimen is found

- The feature $A_{c 2} / A_{e 1}$ has linear relationship with the depth of the crack 

specimen used for absorber tubes of CSP applications via EMAT

3 Liang Cheng ${ }^{* 1}$, Maria Kogia ${ }^{1}$, Abbas Mohimi ${ }^{1,2}$, Vassilios Kappatos ${ }^{1}$, Cem Selcuk ${ }^{1}$, Tat-Hean Gan ${ }^{* 1,2}$

${ }^{1}$ Brunel Innovation Centre, Brunel University, Granta Park, Great Abington, Cambridge, CB21 6AL United Kingdom

${ }^{2}$ TWI Ltd, Cambridge, CB21 6AL, United Kingdom

*Corresponding authors: bic@brunel.ac.uk, liang.cheng@brunel.ac.uk, Tat-Hean.Gan@brunel.ac.uk

\section{Abstract:}

Absorber tubes are one of the most critical components of parabolic trough Concentrated Solar Plants (CSPs). Due to the high temperatures where these tubes perform at with concentration of sunlight, it is very likely for them to get damaged such as crack and mass loss etc., and lose functionality of power generation. Therefore, the monitoring of their structural health via Non-Destructive Testing (NDT) techniques is regarded as essential for preventing them from being significantly defective and thereby reducing maintenance cost. Non-contact method is one of the best inspection candidates, which is more reliable to the tubes at high temperature through a review and the access to the absorber tubes is limited. In this paper, the crack detection and quantification for stainless steel specimen used for absorber tube using Electromagnetic Acoustic Transducers (EMATs) is presented. Through numerical and experimental studies, features are extracted to quantify the crack. Among these features, the ratio between the first edge echo and the second crack echo $\left(\mathrm{A}_{\mathrm{c} 2} / \mathrm{A}_{\mathrm{e} 1}\right)$ is investigated as invariable feature to factors such as electromagnetic coupling, lift-off distance between EMATs and the specimen etc. In addition, the feature $A_{c 2} / A_{e 1}$ has linear relationship with the depth of the crack when the depth is more than $0.75 \mathrm{~mm}$, which proves the feature $\mathrm{A}_{\mathrm{c} 2} / \mathrm{A}_{\mathrm{e} 1}$ is invariable for crack quantification via both numerical modelling and experimental studies.

Key words: Electromagnetic acoustic transducer, stainless steel, crack, nondestructive testing and evaluation, invariable feature

\section{Introduction}

As the greenhouse effect on the climate across the world grows, there is an increasing need for more stable renewable sources of energy as alternative means for environmentally friendly power generation. Concentrated Solar Power (CSP) plant is a promising technology for renewable energy production. By the end of 2014 there were thirty-five CSP plants producing more than $2.5 \mathrm{GW}$ of power in Europe [1]. This represented more than $55 \%$ of the total global CSP capacity amounted to a total CSP production capacity of $4.4 \mathrm{GW}$. Outside Europe there were eleven CSP plants in the US with four of the biggest ones having been completed in 2014, three in China and twelve in the rest of the world. As of early 2015, there were twenty-two CSP plants under construction around the world which will add another 2.5 GW of capacity by 2015 (265 MW installed in Europe) [2]. Several more CSP projects have been announced around the world. If all of them materialise they will add another $9 \mathrm{GW}$ of CSP capacity by 2025 . At the moment, Spain is the European and world leader in the exploitation of CSP technology with the U.S. and China following. In the U.S. the total 
the grid. By 2020 it is anticipated that the U.S. and China will have closed the gap with Europe considerably. Nonetheless, itis expected that at least in the medium term Spain will retain its global leadership in total installed CSP capacity.

CSP plants consist of several kilometres of solar absorber tubes and insulated pipes working at a high temperature up to $550^{\circ} \mathrm{C}$. The inspection of CSP tubing and piping, absorber tubes in particular, is currently very challenging due to their complex design which offers poor access to the surfaces requiring inspection. Mahoney from Sandia National Laboratories reported a failure rate of $30-40 \%$ in solar absorbers at the Solar Energy Generating Systems within a decade of operation [3]. The price of replacement was expensive resulting in a significant extra maintenance cost on an annual basis [3]. Failures can also result in significant leaks and fires due to combustion of the oil commonly used as working fluid in the majority of CSP plants resulting in further significant infrastructure damage [4]. Pitting and general corrosion of the solar receiver and insulated pipes is one of the most common structural degradation mechanisms. Operation at a wide temperature range involving repeated heating and cooling cycles may result in more aggressive forms of corrosion [5]. Corrosion and Stress Corrosion Cracking (SCC) can lead to sudden and catastrophic failure, especially in plants operating at high pressure [6]-[7]. Local pitting corrosion can cause initiation of stress corrosion cracking or result in small-scale leaks. Most stainless steel pipes are vulnerable to pitting corrosion and stress corrosion cracking [8].

At the moment there is no reliable methodology for the inspection of in-service solar receivers and insulated pipes and therefore CSP plant maintenance procedures are corrective rather than preventive. Therefore there is an urgent need to increase the reliability of CSP infrastructure and optimise maintenance procedures by using efficient and cost-effective inspection methods. In ref [9], a comparison of the advantages and disadvantages of the nondestructive testing and evaluation (NDT\&E) methods available to CSP plant operators is shown in Table 1. The compared NDT\&E methods include magnetic flux leakage (MFL) [10]-[12], eddy current testing (ECT) [13]-[16], alternating current field measurement (ACFM) [17]-[18], radiographic inspection (RI) [19]-[21], ultrasonic testing (UT) [22]-[23], long range ultrasonic testing (LRUT) [24]-[26], electromagnetic acoustic transducer (EMAT) [27]-[28], infrared thermography (IR) [29]-[32], acoustic emission (AE) [33]-[34], etc.

Table 1 Comparison of advantages and disadvantages of NDT\&E methods for CSP plant inspection

\begin{tabular}{|c|c|c|c|}
\hline $\begin{array}{c}\text { Te } \\
\text { chniq } \\
\text { ue }\end{array}$ & Advantages & Disadvantages & $\begin{array}{c}\text { Detection } \\
\text { capability }\end{array}$ \\
\hline & $\begin{array}{c}\text { Fast, sensitive to transverse } \\
\text { cracks and corrosion, applicable } \\
\text { for surface and hidden defects, } \\
\text { applicable on some ferrous pipes } \\
\text { and storage tanks walls and floor, } \\
\text { can be automated, low lift-off } \\
\text { sensitivity, pigging compatible }\end{array}$ & $\begin{array}{c}\text { Only ferrous pipes and storage } \\
\text { tanks, defect geometry influences } \\
\text { quantification, parallel cracks can } \\
\text { be missed, if wall thickness loss is } \\
\text { gradual can go undetected, local } \\
\text { inspection, requires good } \\
\text { magnetisation to avoid } \\
\text { FLderestimation or missed defects, } \\
\text { bulky equipment }\end{array}$ & $\begin{array}{c}\text { Surface and } \\
\text { hidden corrosion } \\
\text { and fatigue } \\
\text { cracks, } \\
\text { inclusions }\end{array}$ \\
\hline
\end{tabular}




\begin{tabular}{|c|c|c|c|}
\hline $\begin{array}{l}\mathrm{EC} \\
\mathrm{T}\end{array}$ & $\begin{array}{l}\text { Inexpensive, sensitive to } \\
\text { microstructural, electric and } \\
\text { magnetic properties, sensitive to } \\
\text { small defects, applicable to any } \\
\text { conductive material, pigging } \\
\text { compatible, can be automated, can } \\
\text { operate at significant lift-offs }\end{array}$ & $\begin{array}{l}\text { Very lift-off sensitive, } \\
\text { inspection penetration depth and } \\
\text { resolution dependent on frequency, } \\
\text { local inspection, more efficient for } \\
\text { surface and near-surface } \\
\text { inspection, low resolution in high } \\
\text { lift-offs }\end{array}$ & $\begin{array}{l}\text { Surface and } \\
\text { near-surface } \\
\text { defects (cracks } \\
\text { and pitting } \\
\text { corrosion), } \\
\text { general } \\
\text { corrosion, } \\
\text { microstructural } \\
\text { changes }\end{array}$ \\
\hline $\begin{array}{l}\text { AC } \\
\text { FM }\end{array}$ & $\begin{array}{l}\text { Inexpensive, sensitive to small } \\
\text { defects, capable of quantifying } \\
\text { depth and length of surface- } \\
\text { breaking defects, pigging } \\
\text { compatible, can be automated, can } \\
\text { operate at significant lift-offs }\end{array}$ & $\begin{array}{l}\text { Only surface-breaking defects, } \\
\text { local inspection, quantification } \\
\text { only possible for fatigue cracks }\end{array}$ & $\begin{array}{l}\text { Surface- } \\
\text { breaking defects } \\
\text { including pitting } \\
\text { corrosion and } \\
\text { fatigue cracks }\end{array}$ \\
\hline $\mathrm{RI}$ & $\begin{array}{l}\text { Accurate, does not require } \\
\text { removal of the insulation of glass } \\
\text { envelope, provides permanent } \\
\text { record, can be digitised, can } \\
\text { quantify wall loss in insulated } \\
\text { pipes, can inspect weld quality, } \\
\text { applicable to all components }\end{array}$ & $\begin{array}{l}\text { Health and safety issues, time } \\
\text { consuming, local inspection, } \\
\text { requires access from both sides, } \\
\text { bulky and expensive equipment if } \\
\text { digital detectors and portable X- } \\
\text { ray sources are used, very difficult } \\
\text { to detect cracks }\end{array}$ & $\begin{array}{l}\text { Internal and } \\
\text { surface defects } \\
\text { associated with } \\
\text { corrosion and } \\
\text { weld inclusions }\end{array}$ \\
\hline UT & $\begin{array}{l}\text { Relatively inexpensive unless } \\
\text { phased arrays are used, capable of } \\
\text { detecting hidden defects and } \\
\text { quantifying both hidden and } \\
\text { surface-breaking defects, can be } \\
\text { applied to any type of material }\end{array}$ & $\begin{array}{l}\text { Not applicable to solar absorber } \\
\text { tubes, requires removal of } \\
\text { insulation, local inspection }\end{array}$ & $\begin{array}{l}\text { Internal and } \\
\text { surface defects } \\
\text { including fatigue } \\
\text { cracks and } \\
\text { corrosion }\end{array}$ \\
\hline $\begin{array}{l}\text { LR } \\
\text { UT }\end{array}$ & $\begin{array}{l}\text { Relatively fast, capable of } \\
\text { detecting large hidden and surface } \\
\text { breaking defects, can be applied to } \\
\text { any type of material, can inspect } \\
\text { long sections up to several tens of } \\
\text { metres in one go, requires removal } \\
\text { of insulation only in the area of } \\
\text { installation }\end{array}$ & $\begin{array}{l}\text { Only simple geometries can be } \\
\text { inspected (i.e. pipes), considerable } \\
\text { dead zone, defects need to be } \\
\text { relatively large to be detectable, } \\
\text { signal to noise ratio can be } \\
\text { affected by the inspection } \\
\text { conditions (e.g. presence of tight } \\
\text { insulation, working fluid, etc.) }\end{array}$ & $\begin{array}{l}\text { Relatively } \\
\text { severe corrosion } \\
\text { and transverse } \\
\text { cracks }\end{array}$ \\
\hline $\begin{array}{r}\text { E } \\
\text { MAT }\end{array}$ & $\begin{array}{l}\text { Inexpensive, non-contact, no } \\
\text { material limitation as long as it is } \\
\text { conductive, can detect both hidden } \\
\text { and surface-breaking defect, can } \\
\text { be local or long range, can be } \\
\text { applied at high temperature, easy } \\
\text { to produce specific waves and } \\
\text { modes }\end{array}$ & $\begin{array}{l}\text { Low signal to noise ratio, } \\
\text { sensor requires cooling at high } \\
\text { temperatures, bulky sensors, lift- } \\
\text { off cannot exceed } 2 \mathrm{~mm}\end{array}$ & $\begin{array}{l}\text { Surface and } \\
\text { hidden defects } \\
\text { including } \\
\text { corrosion and } \\
\text { fatigue cracks }\end{array}$ \\
\hline IR & $\begin{array}{l}\text { Fast and global, excellent for } \\
\text { the detection of heat losses, can } \\
\text { detect leaks }\end{array}$ & $\begin{array}{l}\text { Difficult to detect structural } \\
\text { defects, can be affected by } \\
\text { surroundings, expensive } \\
\text { equipment }\end{array}$ & $\begin{array}{l}\text { Heat losses } \\
\text { and leak } \\
\text { detection }\end{array}$ \\
\hline $\mathrm{AE}$ & $\begin{array}{l}\text { Continuous monitoring, can be } \\
\text { applied for detection of crack } \\
\text { initiation and propagation, }\end{array}$ & $\begin{array}{l}\text { No quantitative information of } \\
\text { damage, influenced adversely by } \\
\text { noise sources, can be expensive, }\end{array}$ & $\begin{array}{c}\text { Corrosion, } \\
\text { cracking, leaks }\end{array}$ \\
\hline
\end{tabular}




\begin{tabular}{|l|c|c|c|}
\hline $\begin{array}{c}\text { detection of corrosion debris, long } \\
\text { term monitoring, can be used at } \\
\text { high temperature }\end{array}$ & complicated data management & \\
\hline
\end{tabular}

Among the NDT techniques mentioned above, non-contact UGW can be seen as a good candidate for this application, because it is capable of non-contact ultrasound generation and reception with a large coverage of inspection range. EMAT transducers are highly appropriate for the generation of UGW without contact, because the ultrasound is directly generated within the material. Due to the couplant-free feature, EMATs are particularly useful for automated inspection, and hot, cold, clean, or dry environments. EMAT are ideal transducers for generating Shear Horizontal (SH) bulk wave mode [27], Surface Wave, Lamb waves [28] and all sorts of other guided-wave modes in metallic and/or ferromagnetic materials.

Several attempts to measure the size of cracks using EMAT have been carried out [35][39]. Wilcox et al [35] extracted voltages in frequency domain of A0 and S0 wave mode to quantify the depth of the crack in aluminium plate. Dixon et al [36] used the amplitude of A1, $\mathrm{S} 1$ and A2 extracted from frequency response to describe the crack in different thickness of the plate. Bemstein et al also used the magnitude in frequency domain for crack characterisation. Her et al [38] found the crack leads to the time delay between the two pulses deduced from the frequency spectrum. Edwards et al [39] measured the depth of cracks using the amplitude of the first received echo in time-domain, showing the amplitude of the first echo decreases when the depth of the crack increases. All above approaches using amplitudes as a feature are valid with an assumption of the lift-off or coupling between EMAT and specimen are constant. Once the lift-off or coupling condition varied during the experiment due to surface condition or local property variation of the specimen, the amplitude will be changed significantly. In that case, the feature is no longer valid for accurate approximation of the depth of the crack. In this paper, an invariable feature to the variation of lift-off or coupling condition will be investigated and validated via both simulation and experiment.

The rest of the paper is organised as follows: Section 2 introduces the theoretical background of EMAT; Sections 3 and 4 focus on the simulation and experimental studies on the sizing of the depth of crack via selected features, respectively. A conclusion of the findings from the studies is drawn in Section 5.

\section{Theoretical background of EMAT}

There are two mechanisms to generate waves through magnetic field interaction. One is Lorentz force, when the material is conductive, and the other is magnetostriction when the material is ferromagnetic. In this application, the materials used for absorber tubes are austenitic stainless steel grades which are paramagnetic. Therefore, Lorentz force is the dominant factor for the generation of ultrasound.

Lorentz force is generated by the alternating current (AC) in the electric coil inducing eddy currents on the thin skin of the material. Due to skin effect, the distribution of eddy current is only at a thin layer of the material. Eddy current in the magnetic field experiences 
110 Lorentz force. The Lorentz force is applied on the surface region of the material, governed by

111 following equation:

$$
\boldsymbol{f}=q \mathbf{E}+\mathbf{J} \times \mathbf{B}
$$

where $\boldsymbol{f}$ is Lorentz force density (force per unit volume), $q$ is the charge density (charge per unit volume), $\mathbf{E}$ is the electric field, $\mathbf{J}$ is the current density and $\mathbf{B}$ is the magnetic flux density. When there is no charge, the equation can be rewritten as:

$$
f=\mathrm{J} \times \mathbf{B}
$$

Then the tensor of $\boldsymbol{f}$ can be written in $\mathrm{x}, \mathrm{y}, \mathrm{z}$ coordination as:

$$
f_{\mathrm{x}}=J_{\mathrm{y}} B_{\mathrm{z}}-J_{\mathrm{z}} B_{\mathrm{y}}
$$$$
f_{\mathrm{y}}=J_{\mathrm{z}} B_{\mathrm{x}}-J_{\mathrm{x}} B_{\mathrm{z}}
$$$$
f_{\mathrm{z}}=J_{\mathrm{x}} B_{\mathrm{y}}-J_{\mathrm{y}} B_{\mathrm{x}}
$$

A ferromagnetic material undergoing a dimensional change due to an external magnetic field being applied is referred to as magnetostrictive. The phenomenon is called magnetostriction, and the change is affected by the magnitude and direction of the field [40]. The AC in the electric coil induces an AC magnetic field and thus produces magnetostriction at ultrasonic frequency in the material. The disturbances caused by magnetostriction then propagate in the material as an ultrasound wave.

In this application, the major material for absorber tube is paramagnetic austenitic stainless steel as mentioned earlier with a relative magnetic permeability $\mu_{r}=1.008$. Therefore, Lorentz force is the main consideration for ultrasound generation.

\section{Numerical modelling for crack detection and quantification}

\section{a. Finite element method using COMSOL Multi-physics}

Finite Element Method (FEM) techniques, based on numerical solutions of Partial Differential Equations (PDEs), offer a method for finding approximate numerical solutions of the coupling of electromagnetics and ultrasonics for EMAT. The solution approach involves either eliminating the differential equations completely or rendering the PDEs into an approximating system of ordinary differential equations, which are then solved numerically by integration using standard techniques such as Euler's method [41]. By using COMSOL, models of the Lorentz force generated by coupled electromagnetic field excited by magnets and coils and the propagation of ultrasound is possible to be determined with a reasonable accuracy. This can be performed using time dependant analysis in the magnetic field, magnetic field without currents and structural mechanics modules.

- Magnetic field module is used to solve the induced currents $\boldsymbol{J}_{e}$ (or called eddy currents) in the test sample excited by coils.

- Magnetic field without currents module is implemented to calculate the static magnetic field $\boldsymbol{B}_{s}$ generated by magnets. 
- Lorentz force can be calculated according to $\boldsymbol{J}_{e}$ and $\boldsymbol{B}_{s}$ governing equation $\boldsymbol{f}=\boldsymbol{J}_{e} \times \boldsymbol{B}_{s}$. Then, solid mechanics module is utilised to model the ultrasound generated in the test sample with respect to Lorentz force.

According to the convergence study completed [42], the minimum number of elements required for a wavelength to obtain the best approximation of results is 10 . Therefore the maximum element size to be used to define the mesh can be calculated as follows:

$$
\text { Max element size }=\lambda_{\min } / 10
$$

where $\lambda_{\min }$ is the minimum separation between mesh elements.

For the maximum time step, it is governed following equation:

$$
\text { Max time step }=\lambda_{\min } /(10 v)
$$

where $v$ is speed of wave.

\section{b. Numerical model}

In order to focus the energy to cover the inspection of the whole sample up to several metres, Shear Horizontal (SH) mode SH0 is determined as the best option for this application. As a trade-off of propagation range and sensitivity to the defect, a wavelength of $12 \mathrm{~mm}$ is fixed via Periodic Permeant Magnet (PPM) design. SH EMAT working at $256 \mathrm{kHz}$ for the wavelength of $12 \mathrm{~mm}$ is determined for $3 \mathrm{~mm}$-thick plate made of stainless steel 316L. Then an array of PPM and a race-track coil are selected for the EMAT transducers. The design of the EMAT is shown in Figure 1a and this configuration of EMAT developed in COMSOL as shown in Figure 1b, where a Hanning window centred at $256 \mathrm{kHz}$ with five cycles is used for excitation of the coil.

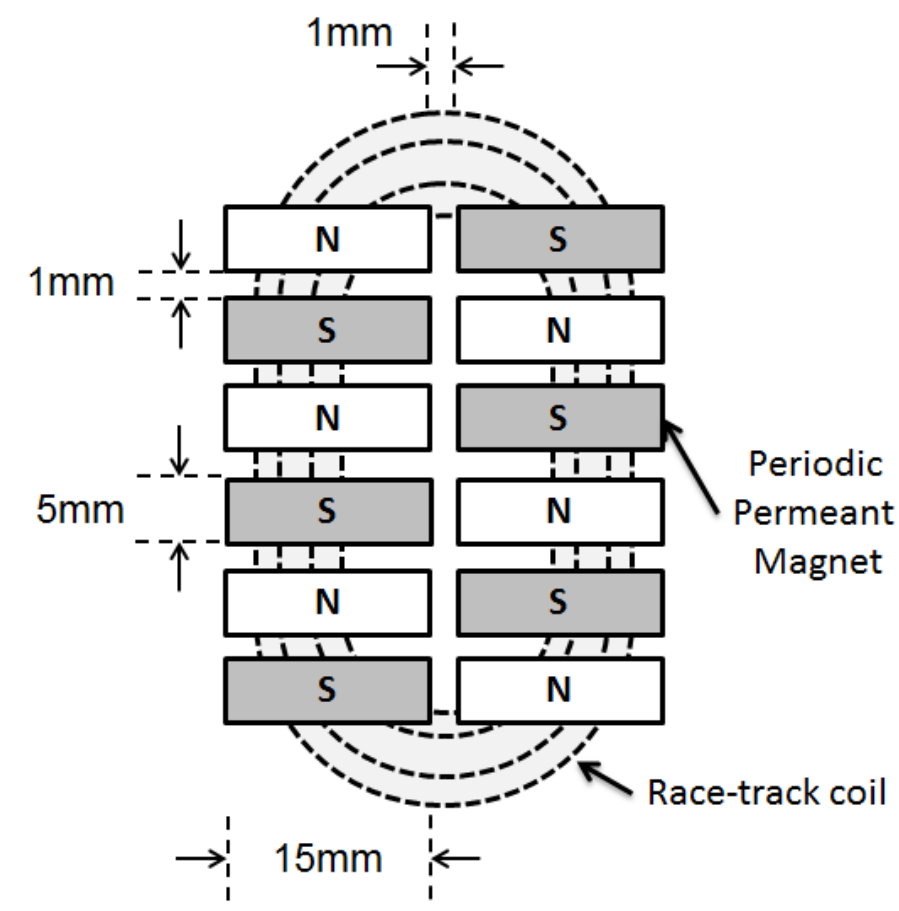

(a) 


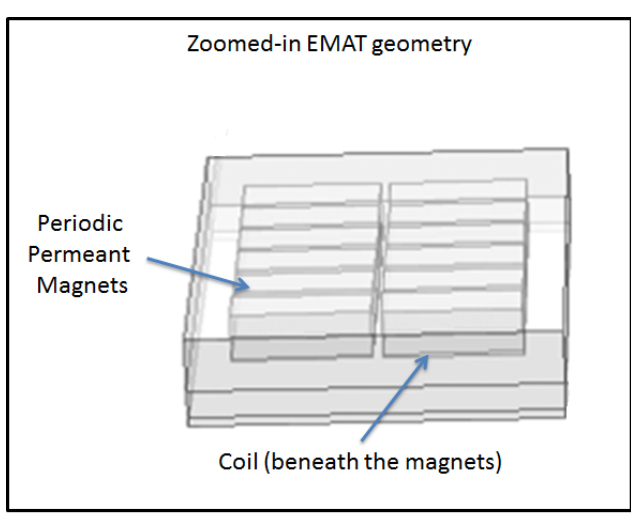

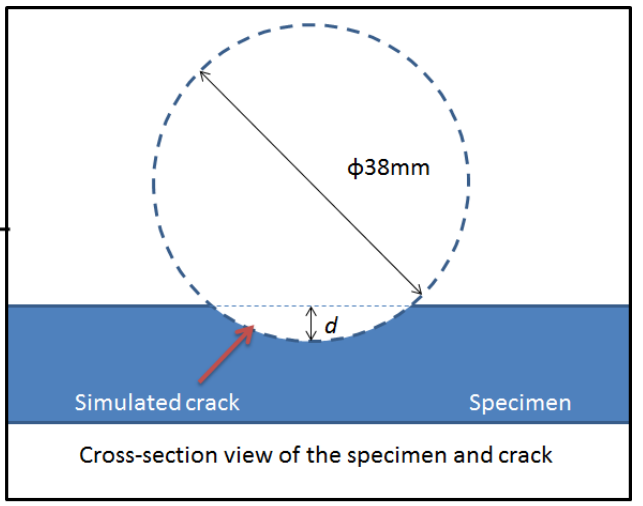

(b)

Figure 1. (a) Design of the EMAT transducer in top view; (b) EMAT model developed in COMSOL for the investigation of cracks.

As illustrated in Figure 1a, the dimension of each magnet is $15 \mathrm{~mm} \times 5 \mathrm{~mm} \times 5 \mathrm{~mm}$. The distance between magnets is $1 \mathrm{~mm}$. In addition, the magnetic strength of each magnet is $0.3 \mathrm{~T}$. The diameter of coil is $0.4 \mathrm{~mm}$ and the width and length are $15 \mathrm{~mm}$ and $35 \mathrm{~mm}$ respectively with a lift-off distance $0.1 \mathrm{~mm}$ to the sample. The excitation current density $J(\mathrm{t})$ is defined as follow:

$$
J(t)\left\{\begin{array}{l}
J_{0} \sin (2 \pi f t)[1-\cos (2 \pi f t / \mathrm{N})], \text { for } t \leq \mathrm{N} / f \\
0, \text { for } t>\mathrm{N} / f
\end{array}\right.
$$

where $J_{0}=1 \mathrm{~A} /(0.4 \mathrm{~mm})^{2}$ (diameter of coil is $\left.0.4 \mathrm{~mm}\right), f=256 \mathrm{kHz}, \mathrm{N}=5$ cycles. The material properties is summarised in Table 2 .

Table 2 Material properties of stainless steel 316Ti at room temperature

\begin{tabular}{|c|c|}
\hline $\begin{array}{c}\text { Young's Modulus } \\
(\mathrm{GPa})\end{array}$ & 195 \\
\hline Poisson Ratio & 0.285 \\
\hline Density $\left(\mathrm{kg} / \mathrm{m}^{3}\right)$ & 8000 \\
\hline $\begin{array}{c}\text { Electrical conductivity } \\
(\mathrm{S} / \mathrm{m})\end{array}$ & $1.45 \mathrm{e} 6$ \\
\hline Permeability & 1.008 \\
\hline Permisivity & 1 \\
\hline
\end{tabular}

As shown in Figure 1b, the simulated crack is created by making the difference between the specimen and a circle disk with the diameter of $38 \mathrm{~mm}$. The circle disk is to simulate the slitting disk of a grander used in experiment to cut the crack with a certain depth. The depth of crack $d$ can be modified by moving the circle disk upwards or downwards in the numerical model. The geometric shape in the cross-sectional view is shown in Figure 1b. The width of the crack is $1 \mathrm{~mm}$ and the tip-totip length of the crack can be calculated via the geometric configuration.

In the numerical model, the length and thickness of the stainless steel plate are $1.25 \mathrm{~m}$ and $3 \mathrm{~mm}$, respectively, which matches the dimension of the specimen used in experimental studies discussed in Section 4 . To reduce the calculation cost, the width is set as $50 \mathrm{~cm}$ while the two boundaries on the 
width sides are set as "continuity" to avoid any reflections from these boundaries. The positions of EMAT transmitter, crack and reception probe are defined in Figure 2. Under this pitch-catch configuration, the expected echoes reflected from only edges of the defect-free sample (denoting as $\mathrm{e}_{1}$, $\mathrm{e}_{2}$, etc.) and additional ones from the crack of defective sample (denoting as $\mathrm{c}_{1}, \mathrm{c}_{2}$, etc.) are shown in the Figure 2.

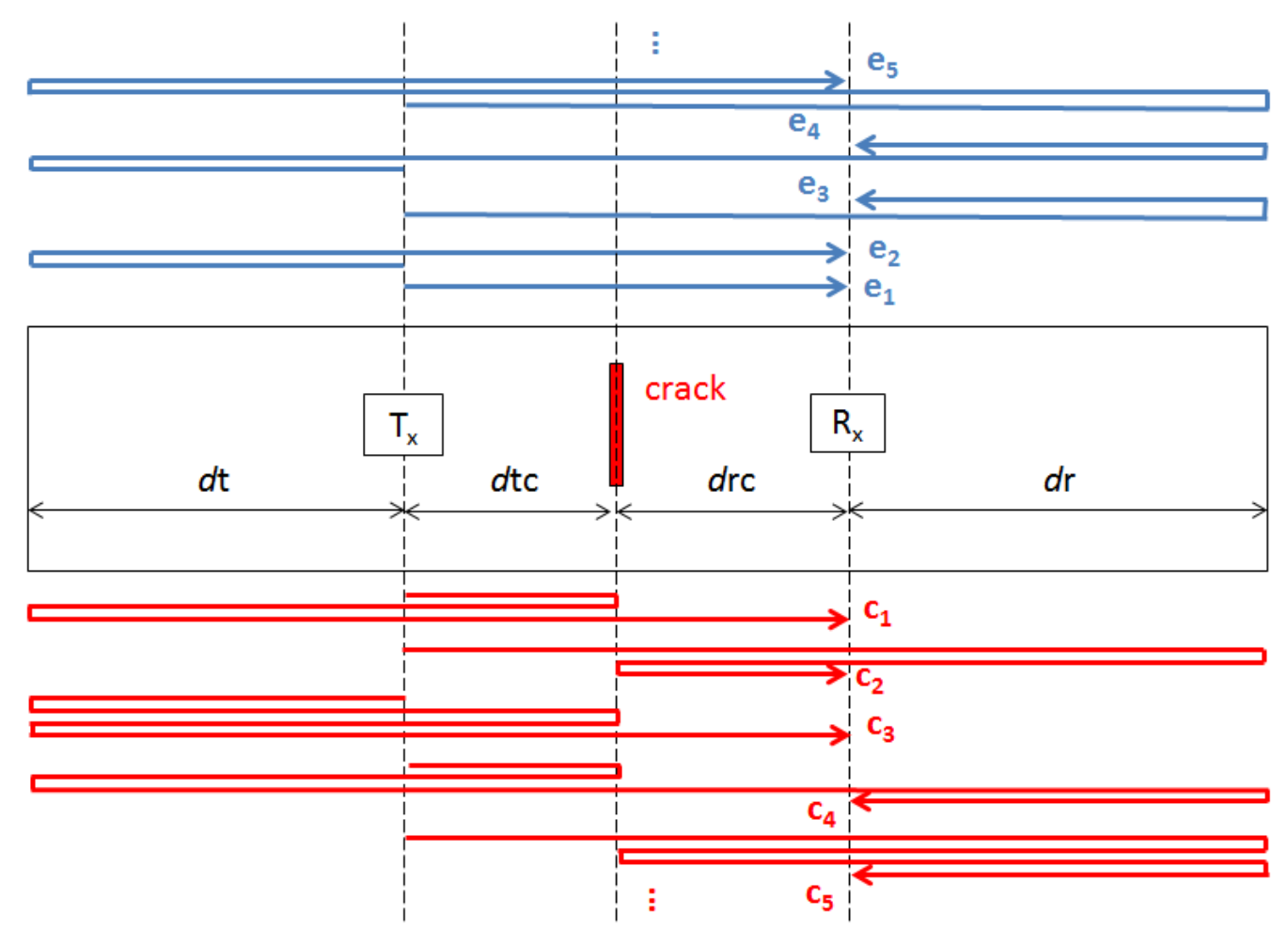

Figure 2 Illustration of the configurations of EMATs and crack with potential echoes to be received for the case $d \mathrm{t}<d \mathrm{r}$ and $d \mathrm{tc}=d \mathrm{rc}$

From above figure, the distances of flight for the echoes $e_{1}$ to $e_{5}$ can be summarised as follows:

$$
\begin{aligned}
& D_{\mathrm{e} 1}=d \mathrm{tc}+d \mathrm{rc} \\
& D_{\mathrm{e} 2}=2 * d \mathrm{t}+d \mathrm{tc}+d \mathrm{rc} \\
& D_{\mathrm{e} 3}=2 * d \mathrm{r}+d \mathrm{tc}+d \mathrm{rc} \\
& D_{\mathrm{e} 4}=2 * d \mathrm{t}+d \mathrm{tc}+d \mathrm{rc}+2 * d \mathrm{r} \\
& D_{\mathrm{e} 5}=2 * d \mathrm{t}+3 * d \mathrm{tc}+3 * d \mathrm{rc}+2 * d \mathrm{r}
\end{aligned}
$$

And the distances of flight for the echoes $c_{1}$ to $c_{5}$ are:

$$
\begin{aligned}
& D \mathrm{c} 1=2 * d \mathrm{t}+3 * d \mathrm{tc}+d \mathrm{rc} \\
& D \mathrm{c} 2=d \mathrm{tc}+3 * d \mathrm{rc}+2 * d \mathrm{r}
\end{aligned}
$$$$
D \mathrm{c} 3=4 * d \mathrm{t}+3 * d \mathrm{tc}+d \mathrm{rc}
$$$$
D \mathrm{c} 4=2 * d \mathrm{t}+3 * d \mathrm{tc}+d \mathrm{rc}+2 * d \mathrm{r}
$$$$
D \mathrm{c} 5=d \mathrm{tc}+3 * d \mathrm{rc}+4 * d \mathrm{r}
$$ 


\section{c. Simulation results for cracks}

218 In the simulation, the values of $d \mathrm{t}, d \mathrm{tc}, d \mathrm{rc}$ and $d \mathrm{r}$ are set as $39 \mathrm{~cm}, 18 \mathrm{~cm}, 18 \mathrm{~cm}$ and $50 \mathrm{~cm}$, 219 respectively to match the configuration in experimental studies. In total, 18 simulations are carried out, including 17 trials with various depths of the crack from $0.25 \mathrm{~mm}$ to $2.9 \mathrm{~mm}$ and one reference for crack-free case. The simulated received signal for crack-free, $1 \mathrm{~mm}, 1.5 \mathrm{~mm}$ and $2 \mathrm{~mm}$ deep crack are shown in Figure 3. A time span to obtain the echoes of $\mathrm{e}_{1}$ to $\mathrm{e}_{4}$ and $\mathrm{c}_{1}$ to $\mathrm{c}_{5}$ is selected as $1 \mathrm{~ms}$.
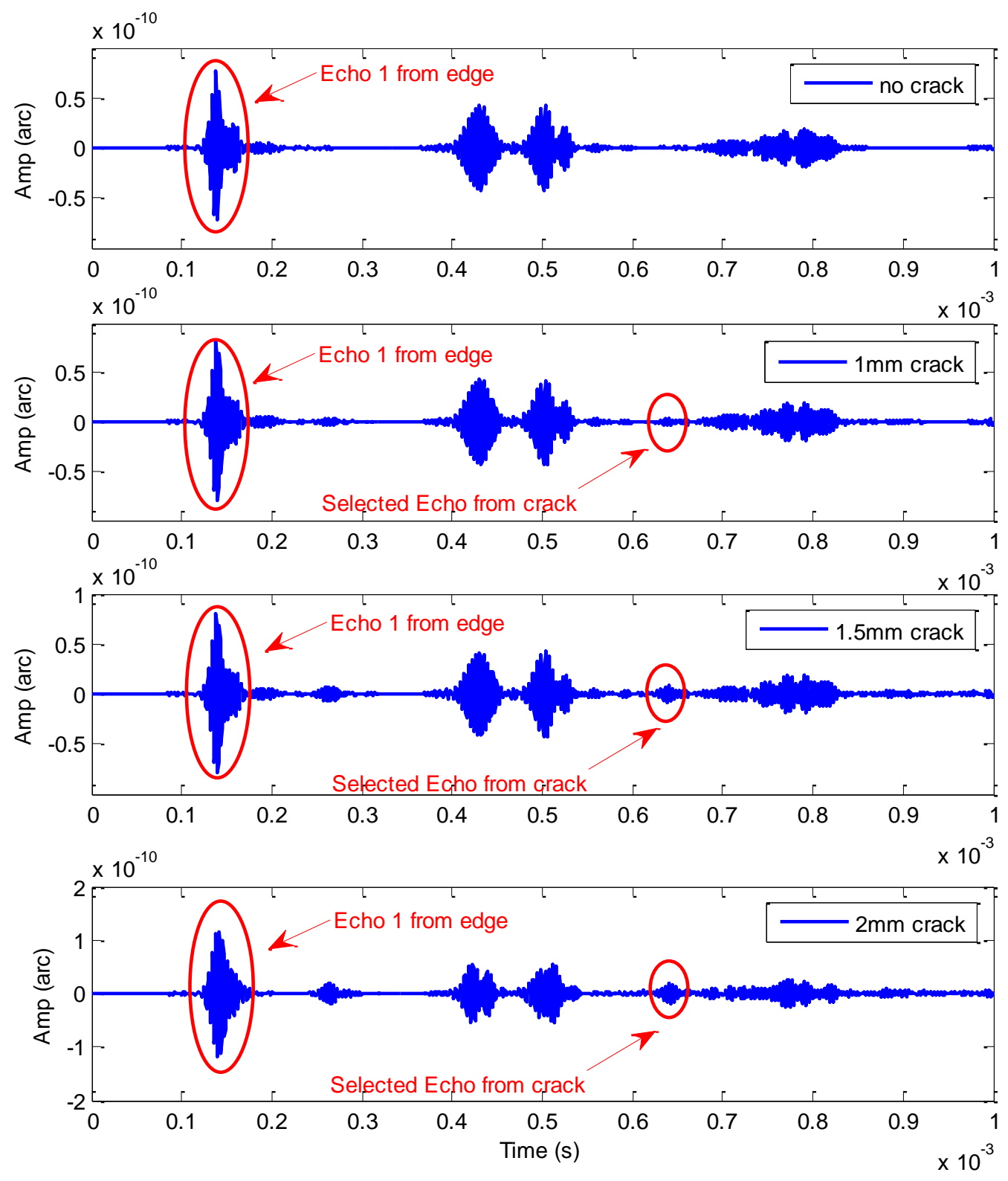

Figure 3 Simulation results of received signals for crack-free, $1 \mathrm{~mm}, 1.5 \mathrm{~mm}$ and $2 \mathrm{~mm}$ deep cracks

Taking $c_{2}$ marked as 'selected echo from crack' in Figure 3 as an example, it can be noticed that the amplitude of $c_{2}\left(A_{c 2}\right)$ increases and the amplitude of $e_{1}\left(A_{e 1}\right)$ decreases when the depths of the crack increases for the four cases shown in Figure 3. The reduction on $A_{e 1}$ 
means that a part of ultrasound energy is reflected backwards and dissipated at the crack when the wave propagates through the crack from the EMAT transmitter to the receiver. As the increase on the crack depth, the energy loss due to the reflection and dissipation at the crack becomes larger, resulting in a reduction on $\mathrm{A}_{\mathrm{e} 1}$. For $\mathrm{c}_{2}$, the ultrasound propagates through the crack firstly, reflects on the right edge of the sample, propagates towards the crack and then reflects back at the crack and finally received at the receiver, which can be seen in Figure 2. For various depths of the crack, the difference is the propagation through and the reflection at the crack for echo $c_{2}$. The overall production of these is an enhancement on the Ac2 from the simulation results. It means the ratio of the reflection at the crack is larger than the loss when the wave propagates through the crack. Therefore, $A_{\mathrm{e} 1}$ and $\mathrm{A}_{\mathrm{c} 2}$ can be used as features to quantify the crack.

However, there is not the only factor of the crack contributing to the amplitudes of the echoes such as $A_{e 1}$ and $A_{c 2}$. In reality, the coupling between EMAT transmitter or receiver and the specimen for different measurement is not always the same. The variation of the coupling conditions will strongly affect the amplitudes of the received echoes, in term of voltages in experimental studies. In addition, the amplitude of echoes is very sensitive to the lift-off distance between the EMAT and the specimen. The amplitude will reduce exponentially when the lift-off increases. Moreover, the temperature also has an influence on the amplitudes. All above factors in the experiment lead to non-reliable $A_{e 1}$ and $A_{c 2}$ as features to quantify the crack, especially the curved specimen introduces more uncertainties of coupling and lift-off when EMATs are placed on a pipe. In the next sub-section, invariable features will be investigated for the crack quantification regardless with those external factors.

\section{d. Feature extraction and crack quantification}

As discussed in Section 3c, features such as $A_{e 1}$ and $A_{c 2}$ can only work at ideal situation. The most common and inevitable influence in experimental studies is the lift-off variation. In order to eliminate the influence from external factors, such as lift-off, on the stability of the feature, the ratio between $\mathrm{A}_{\mathrm{c} 2}$ and $\mathrm{A}_{\mathrm{e} 1}$ in $\mathrm{dB}\left(20 * \log \left(\mathrm{A}_{\mathrm{c} 2} / \mathrm{A}_{\mathrm{e} 1}\right)\right)$ is selected. It can assume that the loss of propagation through and dissipation at the crack when the ultrasound pass through the crack is a function of the depths of defect, denoting as $P(d)$ in $\mathrm{dB}$; the attenuation of the reflection at the crack is also a function of the depths of defect, denoting as $R(d)$ in $\mathrm{dB}$. The amplitudes of $\mathrm{e}_{1}$ and $\mathrm{c}_{2}$ can be expressed as follows according the propagation paths shown in Figure 2:

$$
\begin{aligned}
& \mathrm{A}_{\mathrm{e} 1}(\mathrm{~dB})=\mathrm{A}_{0}(\mathrm{~dB})+\sigma^{*} d \mathrm{tc}+P(d)+\sigma^{*} d \mathrm{rc} \\
& \mathrm{A}_{\mathrm{c} 2}(\mathrm{~dB})=\mathrm{A}_{0}(\mathrm{~dB})+\sigma^{*} d \mathrm{tc}+P(d)+\sigma^{*} d \mathrm{rc}+\sigma^{*} d \mathrm{r}+\sigma \_ \text {edge }+\sigma^{*}(d \mathrm{r}+d \mathrm{rc})+R(d)+\sigma^{*} d \mathrm{rc}
\end{aligned}
$$

where $\mathrm{A}_{0}$ denotes the amplitude of the ultrasound generated at the EMAT transmitter and propagating towards the right edge of the specimen in Figure 2; $\sigma$ is a linear function denoting the attenuation ratio against distance (unit $\mathrm{dB} / \mathrm{m}$ ); $\sigma_{-}$edge is a constant, denoting the attenuation of the reflection at the edge of the specimen. The value of $\mathrm{A}_{0}$ takes into account of lift-off variation, coupling etc. Because $\mathrm{A}_{\mathrm{e} 1}$ and $\mathrm{A}_{\mathrm{c} 2}$ are obtained in the same measurement, 
the values of $A_{0}$ in equation (9) and (10) are the same. $A_{c 1}$ is not selected because the wave generated from the transmitter propagates towards the left edge of the specimen rather the right edge. In that case, the values of $A_{0}$ for $A_{e 1}$ and $A_{c 1}$ are not necessarily the same even for the same measurement. Subtracting (10) by (9), it comes:

$$
\mathrm{A}_{\mathrm{c} 2} / \mathrm{A}_{\mathrm{e} 1}(\mathrm{~dB})=R(d)+\sigma \_ \text {edge }+\sigma^{*}(2 * d \mathrm{r}+2 * d \mathrm{rc})
$$

For the different depths of the crack, the components $\sigma \_$edge and $\sigma^{*}(2 * d \mathrm{r}+2 * d \mathrm{rc})$ stay unchanged in the equation (11). Therefore, the feature $\mathrm{A}_{\mathrm{c} 2} / \mathrm{A}_{\mathrm{e} 1}$ reflects the function $R(d)$ for the quantification of the crack without influence of other factors discussed above. Table 3 and Figure 4 show the comparison of three features $A_{c 2} / A_{e 1}, A_{c 2}$ and $A_{e 1}$ against the depth of the crack $d$ via numerical modelling.

It can be noticed that $\mathrm{A}_{\mathrm{c} 2} / \mathrm{A}_{\mathrm{e} 1}$ monotonically increases as the $d$ increases without any influence on the variation of lift-offs, where the features $A_{c 2}$ and $A_{e 1}$ suffer from strong influence on the variation of lift-offs for $d=0.25 \mathrm{~mm}$ and $2 \mathrm{~mm}$ cases. In particular, the trace of $\mathrm{A}_{\mathrm{c} 2} / \mathrm{A}_{\mathrm{e} 1}$ against $d$ is likely linear when $d \geq 0.75 \mathrm{~mm}$, which shows the feature $\mathrm{A}_{\mathrm{c} 2} / \mathrm{A}_{\mathrm{e} 1}$ is an invariable and efficient feature for crack quantification. The feature $A_{c 2} / A_{e 1}$ will be also used in experimental studies for the validation in the Section 4.

Table 3 Features of the amplitude of $1^{\text {st }}$ edge echo $\left(A_{\mathrm{e} 1}\right), 2^{\text {nd }}$ crack echo $\left(\mathrm{A}_{\mathrm{c} 2}\right)$ and the ratio between $\mathrm{A}_{\mathrm{c} 2}$ and $\mathrm{A}_{\mathrm{e} 1}\left(\mathrm{~A}_{\mathrm{c} 2} / \mathrm{A}_{\mathrm{e} 1}\right)$ against varied crack depths

\begin{tabular}{|c|c|c|c|c|c|c|c|c|c|}
\hline $\begin{array}{r}d \\
(\mathrm{~mm})\end{array}$ & 0 & $\begin{array}{l}0.25 \\
*\end{array}$ & 0.5 & 0.65 & 0.75 & 0.9 & 1.0 & 1.25 & 1.5 \\
\hline $\mathrm{A}_{\mathrm{c} 2} /$ & - & - & - & - & - & - & - & - & - \\
\hline $\mathrm{A}_{\mathrm{e} 1}(\mathrm{~dB})$ & 37.581 & 36.759 & 35.590 & 34.694 & 32.549 & 29.411 & 27.188 & 23.063 & 20.176 \\
\hline $\mathrm{A}_{\mathrm{c} 2}$ & 0.19 & 0.35 & 0.26 & 0.28 & 0.37 & 0.53 & 0.70 & 1.09 & 1.55 \\
\hline$(\operatorname{arc})$ & 622 & 61 & 09 & 51 & 44 & 44 & 73 & 67 & 67 \\
\hline $\mathrm{A}_{\mathrm{e} 1}$ & 14.8 & 24.5 & 15.7 & 15.4 & 15.8 & 15.7 & 16.1 & 15.6 & 15.8 \\
\hline$(\operatorname{arc})$ & 53 & 2 & 03 & 78 & 77 & 91 & 8 & 04 & 85 \\
\hline $\begin{array}{r}d \\
(\mathrm{~mm})\end{array}$ & 1.75 & $2.0^{*}$ & 2.25 & 2.4 & 2.5 & 2.6 & 2.7 & 2.8 & 2.9 \\
\hline $\mathrm{A}_{\mathrm{c} 2} /$ & - & - & - & - & - & - & - & - & - \\
\hline $\mathrm{A}_{\mathrm{e} 1}(\mathrm{~dB})$ & 17.481 & 16.043 & 13.622 & 12.693 & 12.056 & 11.521 & 11.197 & 10.785 & 10.620 \\
\hline $\mathrm{A}_{\mathrm{c} 2}$ & 2.03 & 3.65 & 3.00 & 3.20 & 3.34 & 3.47 & 3.51 & 3.72 & 3.68 \\
\hline$(\operatorname{arc})$ & 8 & 9 & 2 & 2 & 6 & 9 & 9 & 6 & 1 \\
\hline$A_{e 1}$ & 15.2 & 232 & 14.4 & 13.8 & 13.4 & 13.1 & 12.7 & 12.8 & 12.5 \\
\hline$(\operatorname{arc})$ & 49 & 23.2 & 05 & 06 & 07 & 07 & 72 & 97 & 02 \\
\hline
\end{tabular}

* The lift-off distances for two cases for $d=0.25 \mathrm{~mm}$ and $d=2 \mathrm{~mm}$ are intentionally reduced 

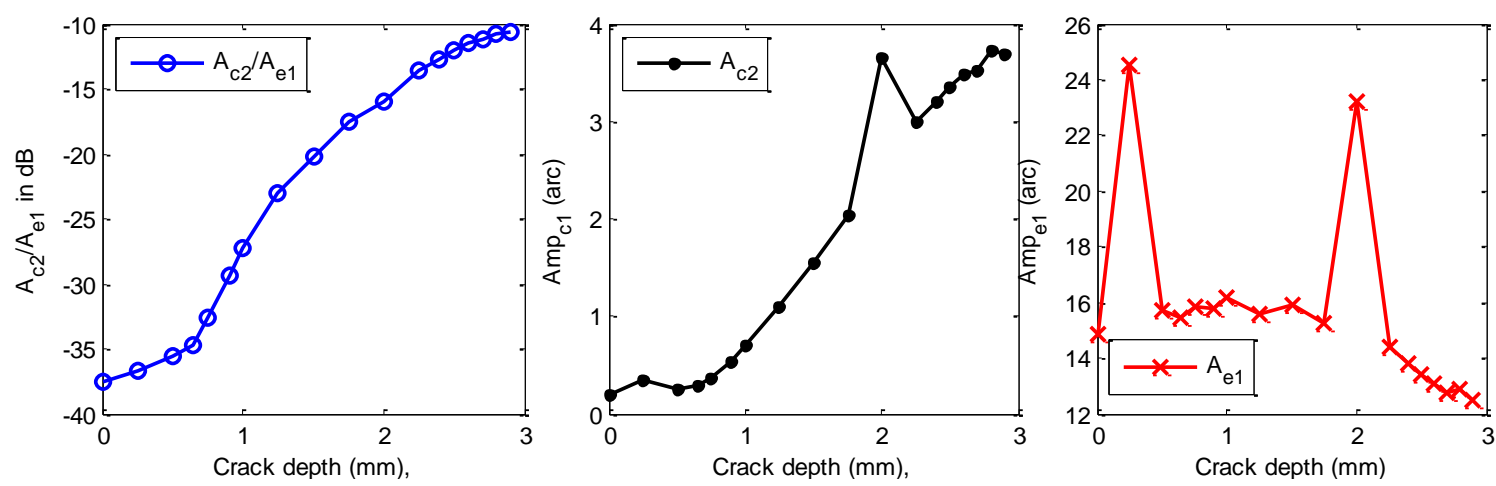

292 Figure 4 Simulation features of the amplitude of $1^{\text {st }}$ edge echo $\left(\mathrm{A}_{\mathrm{e} 1}\right), 2^{\text {nd }}$ crack echo $\left(\mathrm{A}_{\mathrm{c} 2}\right)$ and the ratio between $\mathrm{A}_{\mathrm{c} 2}$ and $\mathrm{A}_{\mathrm{e} 1}\left(\mathrm{~A}_{\mathrm{c} 2} / \mathrm{A}_{\mathrm{e} 1}\right)$ against varied crack depths

\section{Experimental validation}

a. EMAT transducers

A pair of EMATs specifically designed for the inspection of the absorber tubes needs to withstand high temperatures and generate/receive waves of in plane displacement propagating axially over long distances. In this case, $\mathrm{SH} 0$ (or $\mathrm{T}(0,1)$ in pipes) wave mode can be used due to its non-dispersive nature and, therefore, a PPM racetrack coil EMAT can be used for excitation/reception, with the same magnet and coils structure as the design in numerical modelling. The integrated EMAT transducers are shown in Figure 5.

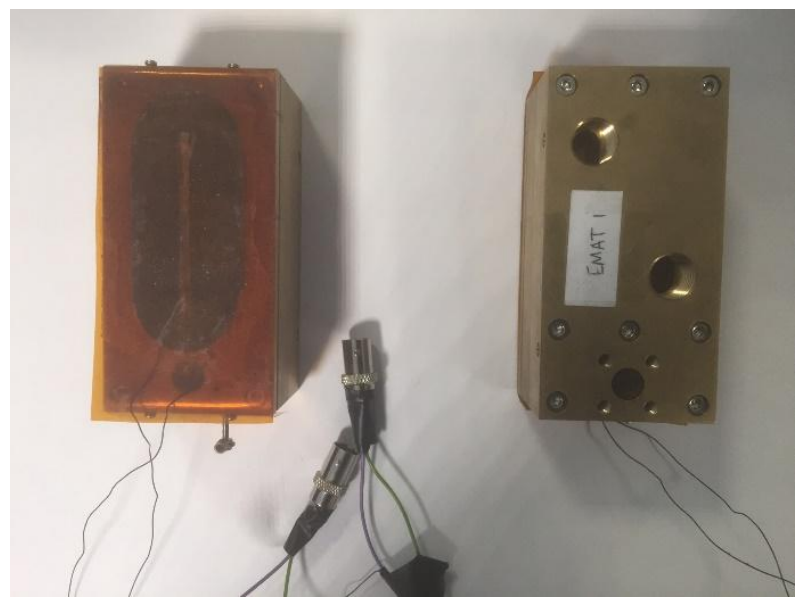

b. Experiment setups

Figure 5 Developed EMAT transducers

EMAT transducers work in pitch-catch mode. EMAT Tx was connected to the transmission port of Ritec via BNC cable and EMAT Rx was linked with the reception port of Ritec. The ports of Ritec along with impedance matching box are shown in Figure 6. A $316 \mathrm{Ti}$ stainless steel plate with the dimension of $1.25 \mathrm{~m} \times 1.25 \mathrm{~m} \times 3 \mathrm{~mm}$ was used to investigate the cracks within stainless steel specimen. The Ritec pulser-receiver was controlled by a computer with Ritec software to set-up the excitation waveform using

311 Hanning with 6 cycles at $256 \mathrm{kHz}$ with maximum power output around $1000 \mathrm{~V}$ peak-to-peak voltage. At reception side, an $80 \mathrm{~dB}$ gain amplifier is used. 


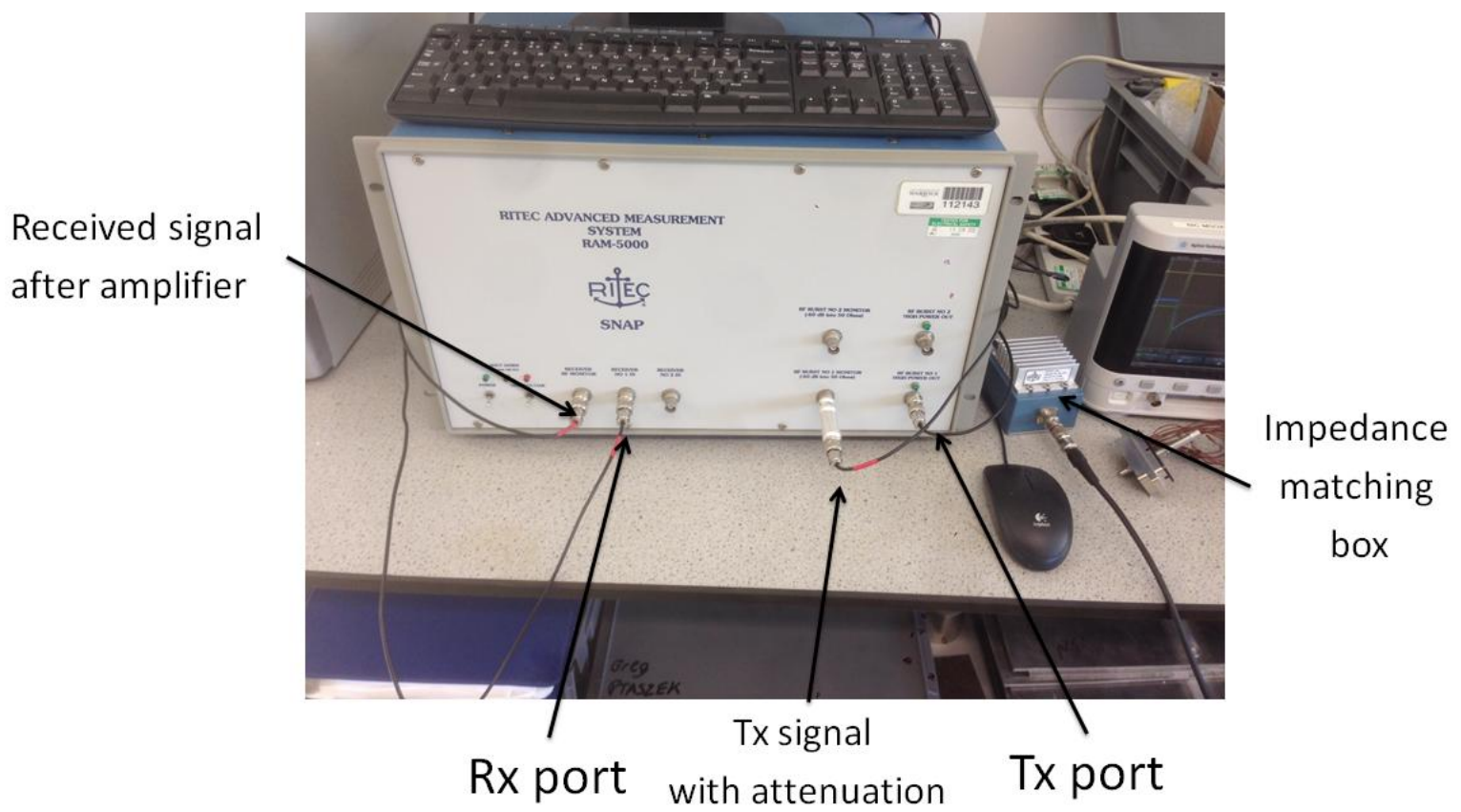

Figure 6 Picture of Ritec pulser-receiver

There are three cracks were manufactured using a grander with a slitting disk with the diameter of $38 \mathrm{~mm}$. Because the cracks were manufactured at different locations, the $d \mathrm{t}$ and $d \mathrm{r}$ values are slightly different. The depths of each crack and its experimental configuration are listed in Table 4. The differences of the values of $d \mathrm{t}$ and $d \mathrm{r}$ are relatively small, therefore, the differences in $\sigma^{*}(2 * d \mathrm{r}+2 * d \mathrm{rc})$ can be ignored.

Table 4 Depths of crack and experiment configuration.

\begin{tabular}{|c|c|c|c|c|c|}
\hline Crack \# & $d(\mathrm{~mm})$ & $d \mathrm{t}(\mathrm{cm})$ & $d \mathrm{r}(\mathrm{cm})$ & $d \mathrm{tc}(\mathrm{cm})$ & $d \mathrm{rc}(\mathrm{cm})$ \\
\hline 1 & 1.130 & 42 & 46.5 & 18 & 18 \\
\hline 2 & 1.442 & 41.5 & 46.5 & 18 & 18 \\
\hline 3 & 1.727 & 39 & 48.5 & 18 & 18 \\
\hline
\end{tabular}

\section{c. Results and validation}

The experiments in pitch-catch mode for crack-free and cracks 1-3 were carried out under the configuration shown in Table 4. The received EMAT signals for these 4 cases are shown in Figure 7. Echoes $e_{1}-e_{4}$ and $c_{1}-c_{5}$ can be seen within the time slot shown in Figure 7. From the results, it can also be noticed that all three cracks can be detected via cracked echo $c_{2}$. In addition, the amplitude of $c_{2}$ for the crack 3 is the largest due to the largest depth of the crack. As the values of $d \mathrm{t}$ and $d \mathrm{r}$ are slightly different for the cracks, the time of arrivals of $\mathrm{e}_{1}$ to $\mathrm{e}_{4}$ are slightly different. The difference between $d \mathrm{t}$ and $d \mathrm{r}$ is the smallest for crack $1, \mathrm{e}_{2}$ and $\mathrm{e}_{3}$ are more close to each other for the signal of crack 1 according to equation (7). 

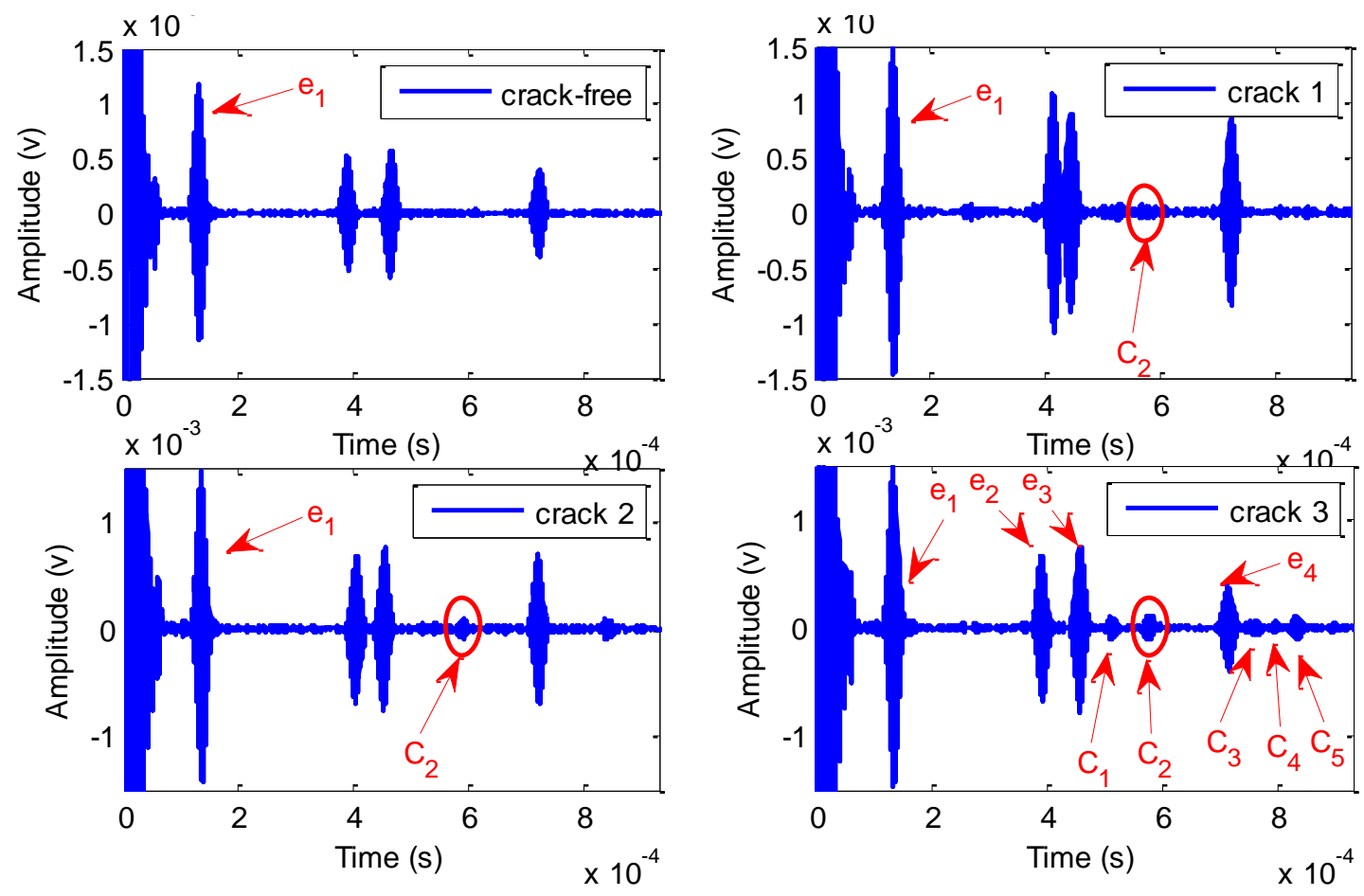

Figure 7 Experiment results of received EMAT signals for crack-free, cracks 1, 2 and 3

After identifying the echoes, the feature $A_{c 2} / A_{e 1}$ for above four experimental case studies is calculated in Table 5. A comparison of $A_{c 2} / A_{e 1}$ derived from numerical and experiment against the depths of the crack is drawn in Figure 8.

Table 5 Experimental feature of the ratio between $A_{c 2}$ and $A_{e 1}\left(A_{c 2} / A_{e 1}\right)$ against varied crack depths

\begin{tabular}{|c|c|c|c|c|}
\hline$d(\mathrm{~mm})$ & 0 & 1.130 & 1.442 & 1.727 \\
\hline $\mathrm{A}_{\mathrm{c} 2} / \mathrm{A}_{\mathrm{e} 1}(\mathrm{~dB})$ & -35.3431 & -28.0003 & -24.2059 & -22.1565 \\
\hline
\end{tabular}

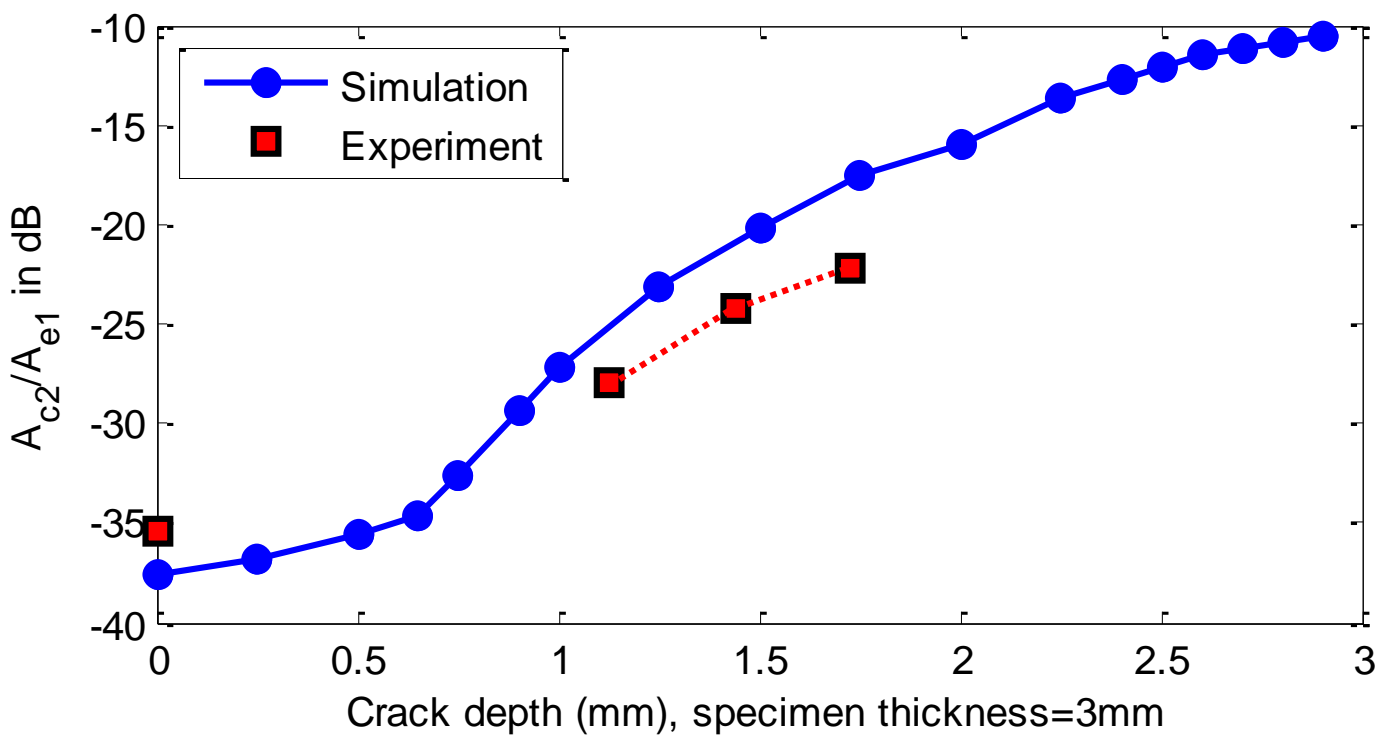

Figure 8 Experimental and numerical results of the feature Ac2/Ae1 in dB against varied depths of the crack 
From Figure 8, it can be noticed that $\mathrm{A}_{\mathrm{c} 2} / \mathrm{A}_{\mathrm{e} 1}$ monotonically increases as the $d$ increases for both simulation and experiment. In particular, the trace of $\mathrm{A}_{\mathrm{c} 2} / \mathrm{A}_{\mathrm{e} 1}$ against $d$ is likely linear when $d \geq 0.75 \mathrm{~mm}$ in simulation and for all three experiment data points. This comparison shows an agreement between simulation and experiment results that the feature $A_{c 2} / A_{e 1}$ is an invariable and efficient feature for crack quantification.

It worth to notice that the experimental result for $d=0 \mathrm{~mm}$ (crack-free) is larger than that of simulation result. When $d=0 \mathrm{~mm}$, the $\mathrm{C} 2$ does not exists because there is no reflection from the crack. The feature $A_{c 2} / A_{e 1}$ is actually the ration between amplitude of noise and $A_{e 1}$, in another word, $A_{c 2} / A_{e 1}$ in $\mathrm{dB}$ becomes $-S N R e_{1}$ (the negative value of the signal-to-noise ratio for echo 1). The SNR for e1 in simulation is always larger than that of experimental value; therefore the absolute value of $\mathrm{A}_{\mathrm{c} 2} / \mathrm{A}_{\mathrm{e} 1}$ of simulation is larger. Moreover, simulation does not take into account or much less than reality of the attenuation of the specimen, dissipation at crack, energy loss at the edge of specimen etc. That leads to the features $A_{c 2}$ $/ \mathrm{A}_{\mathrm{e} 1}$ for cracks in experiment is smaller than the simulation results.

\section{Conclusion}

In this paper, EMAT has been developed for the monitoring of the stainless steel absorber tubes used in CSPs. The periodic permanent magnet (PPM) and race track coil are designed to generate shear horizontal SH0 mode for plate and torsional mode $\mathrm{T}(0,1)$ for pipe.

Through the numerical modelling and experiment, cracks with varied depths in a $3 \mathrm{~mm}$ thick stainless steel specimen can be detected via observation additional echoes $\left(\mathrm{c}_{1}-\mathrm{c}_{5}\right)$ compared the signal from crack-free specimen.

In order to quantify the cracks, three features: the amplitude of the first edge echo $\left(\mathrm{A}_{\mathrm{e} 1}\right)$, the second crack echo $\left(A_{c 2}\right)$ and the ratio between $A_{c 2}$ and $A_{e 1}\left(A_{c 2} / A_{e 1}\right)$ have been investigated. Results showed that $\mathrm{A}_{\mathrm{c} 2} / \mathrm{A}_{\mathrm{e} 1}$ monotonically increases as the $d$ increases without any influence on the variation of lift-offs, where the features $A_{c 2}$ and $A_{e 1}$ suffer from strong influence on the variation of lift-offs. The results showed the feature $A_{\mathrm{c} 2} / \mathrm{A}_{\mathrm{e} 1}$ is an invariable and efficient feature for crack quantification. $A$ validation has been conducted by experiments with three different depths of crack. The comparison of the feature $A_{c 2} / A_{e 1}$ between numerical modelling and experiment showed an agreement on the monotonically increasing relationship of the feature and depth of the crack, in particular, the trace of $\mathrm{A}_{\mathrm{c} 2} / \mathrm{A}_{\mathrm{e} 1}$ against $d$ is likely linear when $d \geq 0.75 \mathrm{~mm}$.

In the future work, more depths of the crack will be manufactured and tested experimentally in order to make the look-up table for the crack quantification. In addition, studies of cracks in the absorber tubes under operation conditions will be carried out to compare the difference between plate and pipe specimens. During INTERSOLAR project, the EMATs were demonstrated in a test rig built in Spain. In the future, an array of EMATs will be validated on the absorber tubes in CSP plants in order to achieve full coverage of the tubes for defect detection, localisation and monitoring.

\section{Acknowledgement}

This study is funded by the FP7 INTERSOLAR project under the Research for the benefit of SMEs programme, Grant Agreement Number 605028. The project is coordinated by CIT 

Service S.A. (Spain), Brunel University (UK), Universidad de Castilla-La Mancha (Spain) and ENGITEC Limited (Cyprus).

\section{Reference}

\section{[1] Concentrated Solar Power Fact Book, SBC Energy Institute, June 2013}

[2] NREL CSP projects database: http://www.nrel.gov/csp/solarpaces/by_project.cfm

[3] R. Mahoney, Trough Technology Heat Collector Element (HCE) Solar Selective Absorbers, Trough Workshop ASES 2000m, June (2000).

[4] MASEN preselects four groups for 500MW Moroccan solar plant, PV Magazine, http://www.pv-magazine.com/news/details/beitrag/masen-preselects-four-groups-for500-mw-morccan-solar-plant_100001884

[5] K. Posteraro, "Thwart Corrosion under Industrial Insulation", Chem. Eng. Progress, Vol. 95, 1999, pp. 43-47.

[6] M. Halliday, "Preventing corrosion under insulation-new generation solutions for an age old problem", Journal of protective coatings \& linings, Vol. 24, 2007, pp. 24-36.

[7] F. De Vogelaere, "Corrosion under insulation", Process Safety Progress, Vol. 28, 2009, pp. 30-35.

[8] M.S. Kumar, M. Sujata, M.A. Venkataswamy, and S.K. Bhaumik, "Failure analysis of a stainless steel pipeline", Engineering Failure Analysis, Vol. 15, 2008, pp. 497-504.

[9] M. Papaelias, L. Cheng, M. Kogia, A. Mohimi, V. Kappatos, C. Selcuk, L. Constantinou, C.Q.G. Muñoz, F.P.G. Marquez and T.-H. Gan, "Inspection and structural health monitoring techniques for concentrated solar power plants", Renewable Energy, vol 85, pp. 1178-1191, 2016

[10] M. Afzal and S. Udpa, "Advanced signal processing of magnetic flux leakage data obtained from seamless gas pipeline", NDT\&E International, Vol. 35, Issue 7, pp. 449457, 2002.

[11] S. Saha, S. Mukhopadhyay, U. Mahapatra, S. Bhattacharya and G.P. Srivastava, "Empirical structure for characterizing metal loss defects from radial magnetic flux leakage signal”, NDT\&E International, Vol. 43, Issue 6, pp. 507-512, 2010.

[12] L. Udpa, S. Udpa and A. Tamburrino, "Adaptive wavelets for characterizing magnetic flux leakage signals from pipeline inspection”, IEEE Transactions on Magnetics, Vol. 42, Issue 10, pp. 3168-3170, 2006.

[13] J. Garcia-Martin, J. Gomez-Gil, and E. Vasquez-Sanchez, "Non-destructive techniques based on eddy current testing", Sensors, Vol. 11, 2011, pp. 2525-2565.

[14] V. Sundararaghavan, K. Balasubramaniam, N.R. Babu and N. Rajesh, "A multifrequency eddy current inversion method for characterizing conductivity gradients on water jet peened components", NDT\&E International, Vol. 38, Issue 7, pp. 541-547, 2005.

[15] G. Y. Tian, A. Sophian, D. Taylor and J. Rudlin, "Multiple sensors on pulsed eddycurrent detection for 3-D subsurface crack assessment", IEEE Sensors Journal, vol 5, isse 1, pp. 90-96, 2005

[16] Y. He, G. Tian, H. Zhang, M. Alamin, A. Simm and P. Jackson, "Steel corrosion characterization using pulsed eddy current systems", IEEE Sensors Journal, vol 12, issue 6, pp. 2113-2120, 2012

[17] M. Lugg and D. Topp, "Recent developments and applications of the ACFM inspection method and ACSM stress measurement method". In Proceedings of the $9^{\text {th }}$ ECNDT, Berlin, Germany, 2006. 
[18] M. Ph. Papaelias, M. C. Lugg, C. Roberts, C. L. Davis, "High-speed inspection of rails using ACFM techniques", NDT \& E International, Vol. 42, 2009, pp. 328-335.

[19] T. Wawrzinek, U. Zscherpel, C. Bellon, "Wall Thickness Determination in Digital Radiography”, COFREND Congress on NDT, Nantes 1997, In Conference proceedings, Vol. 1, pp. 79 -83.

[20] U. Zscherpel, Y. Onel, U. Ewert, "New concepts for corrosion inspection of pipelines by digital industrial radiology (DIR)", In the Proceedings of the $15^{\text {th }}$ WCNDT, Rome, Italy, 2000.

[21] Ron Pincu, "Digital radiography and its advantages in field NDT inspections today", In the Proceedings of the $17^{\text {th }}$ World Conference on Non-Destructive Testing, Shanghai, China, 25-28 October 2008

[22] P. Palanichamy, A. Joseph, T. Jayakumar and B. Raj, "Ultrasonic velocity measurements for estimation of grain size in austenitic stainless steel", $N D T \& E$ International, Vol. 28, Issue 3, 1995, pp. 179-185.

[23] A. Bulavinov, R. Pinchuk, S. Pudovikov, K. M. Reddy and F. Walte, "Industrial application of real-time 3D imaging by sampling phased array", In the Proceedings of the $10^{\text {th }}$ ECNDT, Moscow, Russia, June 2010.

[24] M. G. Silk, K. F. Bainton, The propagation in metal tubing of ultrasonic wave modes equivalent to Lamb waves, Ultrasonics, Vol. 17, 1979, pp. 11-19.

[25] J. L. Rose, J. J. Ditri, A. Pilarski, K. Rajana, K. and F. T. Carr, A guided wave inspection technique for nuclear steam generator tubing, NDT \& E International, Vol. 27, 1994, pp307-330.

[26] D. N. Alleyne, M. J. S. Lowe and P. Cawley, "The reflection of guided waves from circumferential notches in pipes", ASME J Applied Mechanics, Vol. 65, 1998, pp. 635641.

[27] M. Hirao and H. Ogi, "An SH-wave EMAT technique for gas pipeline inspection", NDT \& E Int., Vol. 32, No. 3, 1999, pp. 127-132.

[28] S. Dixon and S.B. Palmer, "Wideband low frequency generation and detection of Lamb and Rayleigh waves using electromagnetic acoustic transducers (EMATs)", Ultrasonics, Vol. 42, 2004, pp. 1129-1136.

[29] M. Pfander, E. Lupfert, P. Pistor, "Infrared temperature measurements on solar trough absorber tubes", Solar Energy, Vol. 81, Issue 6, May 2007, pp. 629-635

[30] Y He, GY Tian, M Pan, D Chen, H Zhang, "An investigation into eddy current pulsed thermography for detection of corrosion blister", Corrosion Science, vol 78, pp. 1-6, 2014

[31] Y. He, G. Tian, M. Pan, D. Chen, "Eddy current pulsed phase thermography and feature extraction", Applied Physics Letters, vol 103, issue 8, pp. 084104, 2013

[32] B. Gao, L. Bai, W. L. Woo, G. Y. Tian, Y. Cheng, "Automatic Defect Identification of Eddy Current Pulsed Thermography Using Single Channel Blind Source Separation", IEEE Transactions on Instrumentation and Measurement, vol 64, issue 4, pp. 913-922, 2014

[33] A. G. Beattie, Acoustic emission principles and instrumentation, Journal of acoustic emission, Vol. 2, Issue 12, 1983, pp. 95-128

[34] A. Berkovits, D. Fang, Study of fatigue crack characteristics by acoustic emission, Engineering Fracture Mechanics, Vol. 51, Issue 3, June 1995, pp. 401-409 and 411416.

[35] P.D. Wilcox, M.J.S. Lowe and P. Cawley, "The excitation and detection of Lamb waves with planar coil electromagnetic acoustic transducers", IEEE Transactions on Ultrasonics, Ferroelectrics, and Frequency Control, vol. 52, No. 12, pp. 2370-2383, 2005 
[36] S. Dixon, S.E. Burrows, B. Dutton and Y. Fan, "Detection of cracks in metal sheets using pulsed laser generated ultrasound and EMAT detection", Ultrasonics, vol. 51, pp. 7-16, 2011.

[37] J.R. Bemstein and J.B. Spicer, "Hybrid laser/broadband EMAT ultrasonic system for characterizing cracks in metals", The Journal of the Acoustical Society of America, vol. 111 No. 4, pp. 1685-1691, 2002.

[38] S.-C. Her and S.-T. Lin, "Non-destructive evaluation of depth of surface cracks using ultrasonic frequency analysis", Sensors, vol. 14, pp. 17146-17158, 2014.

[39] R.S. Edwards, S. Dixon and X. Jian, "Characterisation of defects in the railhead using ultrasonic surface waves", NDT\&E International, vol. 39, pp. 468-575, 2006

[40] M. G. Lozev, R. W. Smith, and B. B. Grimmett, Evaluation of Methods for Detecting and Monitoring of Corrosion Damage in Risers, Journal of Pressure Vessel Technology-transactions of The Asme, vol. 127, (2005)

[41] F. Wang, C.K. Mechefske, Modal Analysis and testing of a thin-walled gradient coil cylinder model, Concepts in Magnetic resonance part $B$ - Magnetic resonance engineering, 27B, 34-50 (2005)

[42] http://prometheus.med.utah.edu/ bwjones/2010/12/lockheed-martin-c-5m-supergalaxy/ 